\title{
Transcript profiling of candidate genes in testis of pigs exhibiting large differences in androstenone levels
}

\author{
Eli Grindflek ${ }^{1 *}$, Ingunn Berget ${ }^{2}$, Maren Moe ${ }^{1}$, Paul Oeth ${ }^{3}$, Sigbjørn Lien ${ }^{2,4}$
}

\begin{abstract}
Background: Boar taint is an unpleasant odor and flavor of the meat and occurs in a high proportion of uncastrated male pigs. Androstenone, a steroid produced in testis and acting as a sex pheromone regulating reproductive function in female pigs, is one of the main compounds responsible for boar taint. The primary goal of the present investigation was to determine the differential gene expression of selected candidate genes related to levels of androstenone in pigs.

Results: Altogether 2560 boars from the Norwegian Landrace and Duroc populations were included in this study. Testicle samples from the 192 boars with most extreme high or low levels of androstenone in fat were used for RNA extraction, and 15 candidate genes were selected and analyzed by real-competitive PCR analysis. The genes Cytochrome P450 C17 (CYP17A1), Steroidogenic acute regulatory protein (STAR), Aldo-keto reductase family 1 member C4 (AKR1C4), Short-chain dehydrogenase/reductase family member 4 (DHRS4), Ferritin light polypeptide (FTL), Sulfotransferase family 2A, dehydroepiandrosterone-preferring member 1 (SULT2A1), Cytochrome P450 subfamily XIA polypeptide 1 (CYP11A1), Cytochrome b5 (CYB5A), and 17-beta-Hydroxysteroid dehydrogenase IV (HSD17B4) were all found to be significantly $(P<0.05)$ up-regulated in high androstenone boars in both Duroc and Landrace. Furthermore, Cytochrome P450 C19A2 (CYP19A2) was down-regulated and progesterone receptor membrane component 1 (PGRMC1) was up-regulated in high-androstenone Duroc boars only, while CYP21 was significantly down-regulated (2.5) in high-androstenone Landrace only. The genes Nuclear Receptor co-activator 4 (NCOA4), Sphingomyrlin phosphodiesterase 1 (SMPD1) and 3ß-hydroxysteroid dehydrogenase (HSD3B) were not significantly differentially expressed in any breeds. Additionally, association studies were performed for the genes with one or more detected SNPS. Association between SNP and androstenone level was observed in CYB5A only, suggesting cis-regulation of the differential transcription in this gene.

Conclusion: A large pig material of highly extreme androstenone levels is investigated. The current study contributes to the knowledge about which genes that is differentially expressed regard to the levels of androstenone in pigs. Results in this paper suggest that several genes are important in the regulation of androstenone level in boars and warrant further evaluation of the above mentioned candidate genes, including analyses in different breeds, identification of causal mutations and possible gene interactions.
\end{abstract}

\section{Background}

Most male pigs used for pork production are castrated very early in life in order to prevent boar taint in the meat. Boar taint is an off-odor/off-flavor primarily caused by high levels of the two compounds androstenone and skatole [1]. Castration is, however, undesirable

\footnotetext{
* Correspondence: eli.grindflek@umb.no

${ }^{1}$ NORSVIN (The Norwegian Pig Breeders Association), Hamar, Norway
}

due to ethical and economical concerns, and because it removes the source of natural anabolic androgens stimulating lean growth. Androstenone is a natural steroid produced by the Leydig cells of the testis in parallel with anabolic hormones [2], and acts as an active sex pheromone regulating reproductive function in female pigs. Due to its lipophilic nature, some androstenone is accumulated in the adipose tissue and produces taint when the fat is heated [3]. Genetics has a large impact
Ciomed Central 
on the levels of androstenone in carcass and heritability estimates are found to range from 0.25 to 0.87 [4,5].

Several studies have aimed at finding the enzymes or key regulatory proteins involved in regulation of androstenone concentrations (reviewed by Robic et al. [6], and Zamaratskaia and Squires [7]), although on a limited number of genes. The primary objective of this study was to test for differential expression in fifteen selected candidate genes involved in the regulation of androstenone levels in pigs. Some of the genes were selected as candidate genes for boar taint due to their biological function, while others were selected on the basis of an earlier microarray gene expression study [8]. The latter set of candidate genes were included in order to confirm earlier findings in another and extended animal material. Recent studies have demonstrated the effect of genetic variation on gene expression levels $[9,10]$. The individual variation in gene expression consists of two varieties; cis-acting which results from DNA variations of a gene that is directly influencing transcription level of that gene, and trans-acting which is due to alteration of other genetic variations. Therefore, we performed an association test examining the phenotypic effects of different alleles for some of the candidate genes ( $C Y B 5 A$, $C Y P 11 A 1, H S D 3 B$ and $N C O A 4)$ displaying differential expression.

\section{Results}

Differential gene expression

A total of 12 out of 15 candidate genes were found to be differentially expressed between high/low androstenone groups at a significance level of $\mathrm{P}<0.001$ to $\mathrm{P}<0.05$ in one or both of the breeds Landrace and Duroc. All the genes significant differentially expressed (Table 1 and 2) were up-regulated in the high-androstenone boars compared to low-androstenone boars, except for CYP19A2 and CYP21 which were down-regulated in the high-androstenone boars. The genes Aldo-keto reductase family 1 member $C 4$ (AKR1C4), CYB5A, Cytochrome P450 c17 (CYP17), CYP11A1, Short-chain dehydrogenase/reductase family member 4 (DHRS4), Ferritin light polypeptide (FTL), 17-beta-Hydroxysteroid dehydrogenase IV (HSD17B4), Steroidogenic acute regulatory protein $(S T A R)$ and Sulfotransferase family $2 \mathrm{~A}$ dehydroepiandrosterone-preferring member 1 (SULT2A1) were all significantly up-regulated in high-androstenone Duroc and Landrace boars. Furthermore, Cytochrome P450 c19A2 (CYP19A2) was down-regulated and progesterone receptor membrane component 1 (PGRMC1) was up-regulated in high-androstenone Duroc boars only, while CYP21 was significantly down-regulated (2.5) in high-androstenone Landrace only. The genes NCOA4, Sphingomyrlin phosphodiesterase 1 (SMPD1) and $H S D 3 B$ were not significantly differentially expressed in any breeds.

\section{Allele-specific differential expression}

Assays were designed for the investigation of allelespecific differential expression of one SNP within $C Y B 5 A$ and two SNPs within each of the genes CYP21 and $H S D 3 B$. Additionally, one assay was made to study differential expression of the CYB5A isoforms 1 and 2. Expression of the $C Y B 5 A$ isoform 2 was, however, not

Table 1 Results from the rCPCR bootstrap statistics $(\times 4000)$, Landrace.

\begin{tabular}{|c|c|c|c|c|c|}
\hline Gene & Fold change $^{a}$ & Log10 Fold change & Bias & Std error & $P$ value \\
\hline AKR1C4 & 2.6 & 0.42 & 0.0050 & 0.11 & 0.0000 \\
\hline CYB5A_-8(5'UTR) & 2.6 & 0.42 & 0.0034 & 0.17 & 0.0090 \\
\hline CYB5A_iso1-2 & 2.4 & 0.37 & 0.0026 & 0.19 & 0.0210 \\
\hline CYP11A1 & 3.1 & 0.50 & 0.0050 & 0.13 & 0.0000 \\
\hline CYP17A1 & 2.9 & 0.46 & 0.0034 & 0.09 & 0.0000 \\
\hline CYP19A2 & 0.8 & -0.10 & -0.0003 & 0.13 & 0.2120 \\
\hline CYP21_exon9 & 0.1 & -0.91 & -0.0033 & 0.46 & 0.0200 \\
\hline DHRS4 & 2.6 & 0.41 & 0.0043 & 0.11 & 0.0005 \\
\hline $\mathrm{FTL}$ & 2.3 & 0.35 & 0.0036 & 0.11 & 0.0005 \\
\hline HSD3B_exon2 & 1.2 & 0.06 & 0.0067 & 0.24 & 0.3810 \\
\hline HSD3B_5'UTR & 0.8 & -0.10 & 0.0023 & 0.20 & 0.3120 \\
\hline HSD17B4 & 2.2 & 0.34 & 0.0034 & 0.12 & 0.0030 \\
\hline NCOA4 & 1.3 & 0.11 & 0.0019 & 0.13 & 0.1970 \\
\hline PGRMC1 & 1.2 & 0.08 & 0.0045 & 0.13 & 0.2700 \\
\hline SMPD1 & 1.1 & 0.04 & 0.0032 & 0.09 & 0.3200 \\
\hline STAR & 13.5 & 1.13 & 0.0032 & 0.14 & 0.0000 \\
\hline SULT2A1 & 3.0 & 0.48 & 0.0031 & 0.13 & 0.0002 \\
\hline
\end{tabular}

${ }^{a}$ Fold changes are calculated relative to baseline, which is the group of low androstenone (LL) in this case, and are therefore indicating the times of upregulation in high-androstenone group compared to the low-androstenone group. All genes are adjusted for the housekeeping gene HPRT. 
Table 2 Results from the rcPCR bootstrap statistics (×4000), Duroc.

\begin{tabular}{|c|c|c|c|c|c|}
\hline Gene & Fold change $^{a}$ & Log10 Fold change & Bias & Std error & $P$ value \\
\hline AKR1C4 & 1.6 & 0.21 & 0.0007 & 0.11 & 0.0270 \\
\hline CYB5A_-8(5'UTR) & 2.0 & 0.31 & -0.0011 & 0.11 & 0.0040 \\
\hline CYB5A_iso1-2 & 1.6 & 0.19 & 0.0030 & 0.15 & 0.0910 \\
\hline CYP11A1 & 2.3 & 0.37 & 0.0006 & 0.12 & 0.0010 \\
\hline CYP17A1 & 2.4 & 0.38 & 0.0004 & 0.11 & 0.0005 \\
\hline CYP19A2 & 0.6 & -0.22 & 0.0002 & 0.12 & 0.0360 \\
\hline CYP21_exon8 & 0.9 & -0.04 & 0.0042 & 0.25 & 0.4380 \\
\hline CYP21_exon9 & 1.0 & 0.01 & 0.1255 & 0.32 & 0.4780 \\
\hline DHRS4 & 2.1 & 0.33 & 0.0011 & 0.11 & 0.0020 \\
\hline FTL & 1.9 & 0.27 & 0.0008 & 0.11 & 0.0090 \\
\hline HSD3B_exon2 & 0.8 & -0.11 & 0.0005 & 0.17 & 0.2490 \\
\hline HSD3B_5'UTR & 1.0 & 0.02 & -0.0011 & 0.15 & 0.4460 \\
\hline HSD17B4 & 1.6 & 0.20 & 0.0002 & 0.11 & 0.0430 \\
\hline NCOA4 & 1.5 & 0.18 & -0.0018 & 0.11 & 0.0620 \\
\hline PGRMC1 & 1.6 & 0.21 & 0.0005 & 0.11 & 0.0330 \\
\hline SMPD1 & 1.1 & 0.03 & 0.0011 & 0.11 & 0.3940 \\
\hline STAR & 4.7 & 0.68 & -0.0009 & 0.12 & 0.0000 \\
\hline SULT2A1 & 2.1 & 0.32 & -0.0004 & 0.11 & 0.0030 \\
\hline
\end{tabular}

${ }^{a}$ Fold changes are calculated relative to baseline, which is the group of low androstenone (LD) in this case, and are therefore indicating the times of upregulation in high-androstenone group compared to the low-androstenone group. All genes are adjusted for the housekeeping gene HPRT.

detected in any of the samples. Also, no significant differential allele-specific expression between high and low androstenone animals (both breeds) was detected in any of the genes investigated (results not shown). For the SNPs in CYB5A (-8(5'UTR)), CYP21 (exon8 and exon9), as well as for the SNPs in HSD3B (-15 (5'UTR)), the two alleles had nearly identical expression levels, with expression levels ratios in the range of 0.46-0.54. For the SNP located in HSD3B exon2, on the other hand, the two alleles were expressed differentially $(\mathrm{P}<0.05)$, although not with regard to the levels of androstenone. In Duroc, allele A had generally higher expression levels than allele $\mathrm{G}$ (average ratio 0.80 ), whereas in Landrace allele A had lower expression levels than allele G (average ratio 0.41). Notably, allele $\mathrm{A}$ is quite rare in both breeds. The allele frequencies used in the assays of allele-specific expression are shown in Table 3.

\section{Association studies}

Five SNPs were detected in the candidate genes $C Y B 5 A$, CYP11A1, HSD3B and NCOA4 (Table 4), and single SNP association studies were performed in both Landrace and Duroc breeds. The SNP located in position -8 of the CYB5A gene was significantly associated to androstenone levels in Duroc $(\mathrm{P}<0.01)$, although it was not reproducible within Landrace $(P=0.14)$. No other SNPs were significantly associated with androstenone in this study (Table 4). Association results including SNPs in some of the other genes investigated in this study have previously been presented in Moe et al. [11].

\section{Discussion}

In the present study, fifteen candidate genes potentially affecting androstenone levels in boars were selected, based on the biochemistry and physiology of the trait, and on results from a microarray study published by Moe et al. [8]. The main objective of the study was to determine whether the genes were differentially expressed in pigs with high and low androstenone levels. Variation in gene expression between different alleles in mammals [12] and genetic variation in single nucleotide polymorphisms (SNPs) within the candidate genes may also contribute to the androstenone variability. Therefore, investigation of allele-specific expression and association tests were also performed for the candidate genes in question.

The synthesis of 16-androstene steroids, including androstenone, occurs by the action of several enzymes and some of them have been found to be more important than others. Members of the Cytochrome P450 superfamily function as monooxygenases, utilizing electrons to catalyze the hydroxylation and cleavage of substrates. The formation of the 16-androstene steroids from pregnenolone is catalyzed by the andien- $\beta$ synthase enzyme system [13]. Major enzymes in this system are CYP17A1 along with CYB5A and the associated reductases [14]. Several studies have previously studied CYB5A as a candidate gene for boar taint [15-17]. Levels of mRNA for total CYB5A were found to be significantly correlated with levels of androstenone in fat [16]. These results are in accordance with our results, showing 
Table 3 Frequency of alleles used in the assays of allele expression, Landrace and Duroc.

\begin{tabular}{|c|c|c|c|c|c|}
\hline Gene, LANDRACE & Genotype & Frequency & Gene, DUROC & Genotype & Frequency \\
\hline \multirow[t]{3}{*}{ HSD3B_5'UTR } & CC & 7 & HSD3B_5'UTR & $\mathrm{CC}$ & 4 \\
\hline & CT & 34 & & $C T$ & 31 \\
\hline & $\pi$ & 55 & & $\pi$ & 60 \\
\hline \multirow[t]{3}{*}{ HSD3B_exon2 } & AA & 1 & HSD3B_exon2 & $\mathrm{AA}$ & 0 \\
\hline & $A G$ & 13 & & $A G$ & 16 \\
\hline & GG & 82 & & GG & 79 \\
\hline \multirow[t]{3}{*}{ CYP21_exon8 } & CC & 8 & CYP21_exon8 & CC & 55 \\
\hline & CT & 32 & & $C T$ & 25 \\
\hline & $\pi$ & 56 & & $\pi$ & 16 \\
\hline \multirow[t]{3}{*}{ CYP21_exon9 } & CC & 64 & CYP21_exon9 & CC & 96 \\
\hline & $\mathrm{CT}$ & 28 & & $C T$ & 0 \\
\hline & $\pi$ & 4 & & $\pi$ & 0 \\
\hline \multirow[t]{3}{*}{ CYB5A_-8(5'UTR) } & GG & 94 & CYB5A_-8(5'UTR) & GG & 89 \\
\hline & GT & 2 & & GT & 6 \\
\hline & $\pi$ & 0 & & $\Pi$ & 0 \\
\hline
\end{tabular}

significant up-regulation of total CYB5A (CYB5A_8 (5'UTR) in Tables 1 and 2) expression in the high androstenone animals in both breeds. Two variants, a soluble (isoform 1) and membrane bound (isoform 2) form, of CYB5A cDNA have been isolated in pigs [18], and later detected as a low molecular weight form (isoform 1) and a high molecular weight form (isoform 2) in porcine testis [16]. The CYB5A isoforms are derived from one mRNA via alternative splicing [19]. A study by Davis et al. [16] found that levels of the CYB5A isoform 1 , but not levels of isoform 2, were correlated with both the rate of 16-androstene steroid synthesis and fat androstenone concentrations, indicating that increased levels of the isoform 1 of $C Y B 5 A$ are linked to a higher level of androstenone production in pig testis. In our study, the assay "CYB5A_iso1-2" (Table 1 and 2) was used to study differential expression between isoform 1 and 2. Results show that the expression of isoform 1 was significantly up-regulated $(\mathrm{P}<0.05)$ in high-androstenone Landrace animals. The Duroc breed did not reached the defined level of significance, although it was rather close $(\mathrm{P}=0.09)$. Expression levels of $C Y B 5 A$ isoform 1 seems to be slightly less up-regulated (although not significantly) compared with total $C Y B 5 A$ expression (Tables 1 and 2). CYB5A isoform 2 was not detected in any of the samples. Another purpose of the assay "CYB5A_-8 (5'UTR)" was to study differences in allelespecific expression of the SNP detected in the 5'UTR, 8 bp upstream of the translation start codon. The results revealed no significant differential allele-specific expression between the high and low androstenone groups. Furthermore, an association study on the same polymorphism in the entire material of Landrace and Duroc, i.e. 2560 boars altogether, were performed. Only homozygous $\mathrm{G}$ and heterozygous GT animals were detected in our populations, reflecting a low frequency of the $\mathrm{T}$ allele which is also seen in other populations $[17,20]$. The polymorphism was found to be significantly associated to androstenone levels in Duroc, but not in Landrace. In both breeds, however, the LS mean values of androstenone were lower in the heterozygous (GT) animals than in the homozygous G genotype (Table 4).

Table 4 The associations between SNPs and levels of androstenone in Duroc and Landrace boars ${ }^{\mathrm{a}}$

\begin{tabular}{|c|c|c|c|c|c|}
\hline B & Gene & Genotype 1 & Genotype $1 / 2$ & Genotype 2 & $P$ value \\
\hline $\mathrm{D}$ & CYB5A_-8(5'UTR) & $\mathrm{G}(\mathrm{n}=902): 3.45( \pm 0.12)$ & $\mathrm{G} / T(\mathrm{n}=51): 2.56( \pm 0.38)$ & - & 0.01 \\
\hline D & HSD3B_-15(5'UTR) & $C(n=67): 2.38( \pm 0.45)$ & $C / T(n=293): 2.70( \pm 0.20)$ & $T(n=409): 3.25( \pm 0.12)$ & 0.11 \\
\hline D & HSD3B_271-exon2 & - & $\mathrm{A} / \mathrm{G}(\mathrm{n}=74): 2.82( \pm 0.11)$ & $G(n=641): 3.03( \pm 0.28)$ & 0.68 \\
\hline D & NCOA4_3'UTR & $A(n=326): 3.48( \pm 0.23)$ & $A G(n=413): 3.49( \pm 0.21)$ & $G(n=180): 3.67( \pm 0.26)$ & 0.22 \\
\hline L & CYB5A_-8(5'UTR) & $G(n=1278): 1.18( \pm 0.04)$ & $G / T(n=25): 0.97( \pm 0.15)$ & - & 0.14 \\
\hline L & CYP11A1_150-exo1 & $A(n=321): 1.05( \pm 0.13)$ & $\mathrm{A} / \mathrm{G}(\mathrm{n}=352): 1.23( \pm 0.11)$ & $G(n=153): 0.96( \pm 0.20)$ & 0.39 \\
\hline$L$ & HSD3B_-15(5'UTR) & $C(n=74): 1.00( \pm 0.19)$ & $C / T(n=267): 1.31( \pm 0.13)$ & $\mathrm{T}(\mathrm{n}=430): 1.02( \pm 0.11)$ & 0.16 \\
\hline L & HSD3B_271-exon2 & $A(n=14): 1.00( \pm 0.21)$ & $\mathrm{A} / \mathrm{G}(\mathrm{n}=94): 0.88( \pm 0.16)$ & $G(n=512): 1.11( \pm 0.29)$ & 0.64 \\
\hline L & NCOA4_3'UTR & $A(n=204): 1.24( \pm 0.09)$ & $\mathrm{A} / \mathrm{G}(\mathrm{n}=530): 1.18( \pm 0.05)$ & $G(n=425): 1.10( \pm 0.06)$ & 0.36 \\
\hline
\end{tabular}

${ }^{a}$ The number of boars is shown between parentheses after each genotype. The least square means are shown for all genotypes and estimated standard errors are shown between the parentheses. Dash is no genotype found. $\mathrm{B}=\mathrm{Breed}, \mathrm{D}=$ Duroc and $\mathrm{L}=$ Norwegian Landrace. 
This trend is in accordance with the results of Lin et al. [15] reporting this SNP allele to be associated with a decrease in fat androstenone production in vivo, as well as $C Y B 5 A$ protein expression in vitro, in a variety of breeds. This is also confirmed by two other studies $[17,20]$. Both differential gene expression and association with androstenone might indicate a Cis-acting regulation of CYB5A expression in pigs. Furthermore, CYB5A is a protein widely involved in biological processes, being a component of electron transfer chains in a number of pathways [21]. For example, interactions between CYB5A and the FTL may affect levels of androstenone through the CYB5A/CYP450 electron transfer [22]. In this study, the FTL was highly up-regulated in both breeds $(\mathrm{P}<0.01)$, which is in agreement with the study of Moe et al. [8]. The FTL gene provides instructions for making the ferritin light chain. Ferritin stores and releases iron in cells and plays a central role in numerous essential cellular functions (reviewed by Hentze and Kuhn [23]).

The major enzymes Cytochrome P450 c17 (CYP17) and CYB5A interacts in the andien- $\beta$ synthase system [13], and since CYP17A1 also converts pregnenolone into precursors of the androgens and estrogens it is also a very potent candidate gene for androstenone production. However, no significant effects have so far been detected in association studies [24] or on the protein expression level [16]. In this study we did, however, find CYP17A1 cDNA levels to be significantly up-regulated in high androstenone boars of both Landrace and Duroc. No SNPs were detected within the CYP17A1 gene in our populations.

The key rate-limiting factor for the maintenance of steroid production is the continuous provision of the cholesterol substrate from the outer mitochondrial membrane to the enzymatic component in the inner membrane, which is mainly facilitated by STAR [25]. Next, the CYP11A1 enzyme, localized to the mitochondrial inner membrane, catalyzes the conversion of cholesterol to pregnenolone in the first and rate-limiting step in the synthesis of the steroid hormones [26]. This is a very important step in the production of androstenone, and interestingly STAR and CYP11A1 are both highly up-regulated in high androstenone animals in both Landrace and Duroc. STAR was found as much as 13.5 times up-regulated in Landrace and 4.7 times upregulated in Duroc. Highly differentiated expression of $S T A R$ was also seen in our previous microarray study [8]. STAR has previously shown increased gene expression during the time of sexual differentiation [27]. Regulation of STAR has, however, been suggested to be both on the post transcriptional level, in a developmental stage- and tissue-specific manner [28], and at transcription level [29]. No SNPs were detected in STAR in this study, and further studies are needed to reveal molecular basis for this variation. Also CYP11A1 was found upregulated in the previous microarray study [8] and confirmed in this study. A SNP located in CYP11A1 exon 1 was not significantly associated with androstenone levels in Landrace boars (Table 4), while no data were obtained for the Duroc breed. In contrast, another polymorphism in CYP11A1 exon 1 has previously been found to be significantly associated with androstenone levels in Yorkshire boars [30], whilst not in a Large White and Meishan cross [31].

Furthermore, sulfotransferase family 2A dehydroepiandrosterone-preferring member 1 (SULT2A1) is a key enzyme in the testicular and hepatic metabolism of $5 \alpha$ androstenone and responsible for sulfoconjugating the 16-androstene steroids. Previous studies have indicated that increased levels of sulfoconjugated 16-androstene steroids present in the systemic circulation are associated with reduction in the accumulation of $5 \alpha$-androstenone in adipose tissue [32]. Additionally, testicular SULT2A1 activity was found to be negatively correlated with $5 \alpha$-androstenone concentrations in fat, SULT2A1 enzyme activity was positively correlated with SULT2A1 protein level, and finally the gene expression level was positively correlated with increased protein level [33]. The findings in our study are, however, contradictory to this since we have an up-regulation of SULT2A1 gene expression level in high androstenone animals (both breeds).

The last steps in the formation of androgens and estrogens are catalyzed by $17 \beta$-hydroxysteroid dehydrogenase (17 $\beta$-HSD) enzymes [34]. Previously, these enzymes have been assigned to porcine Leydig and Sertoli cells [35] and several porcine tissues have been shown to express HSD17B4 as a predominant dehydrogenase [36]. HSD17B4 has also been shown to inactivate estrogens very efficiently in several tissues because of its preference for steroid oxidation [37]. Our study, however, indicate that the HSD17B4 gene is rather up-regulated in testes in both high androstenone Duroc and Landrace boars. Due to this it is important to note that several roles of HSD17B4 are suggested [37]. A study done by Chen et al. [38] did not detect any differences in $H S D 17 B$ gene expression between boars of high and low androstenone in a Landrace $\mathrm{x}$ Yorkshire crossbred. Five SNPs within HSD17B were detected and tested in this population by Moe et al. [11], but no significant associations were detected.

The gene expression of $A K R 1 C 4$, which belongs to the cytosolic aldo-keto reductases that act as $3 \alpha-/ 3 \beta-/ 17 \beta-/$ $20 \alpha$-hydroxysteroid dehydrogenases (HSDs) in human [39], was also investigated. Significant up-regulation of the gene $A K R 1 C 4$ was detected in high androstenone boars in both breeds, although it was more pronounced 
in Landrace (Tables 1 and 2). This is in accordance with results of Moe et al. [8]. All the isoforms AKR1C1AKR1C4 have previously been found to convert active androgens and estrogens to their associated inactive metabolites, preventing excess of circulating steroid hormones and turning the steroids into substrates for conjugation reactions [39]. However, the role of AKR1C4 in regulation of androstenone level in testes needs to be clarified. Members of the dehydrogenase/reductase (SDR) family are other enzymes involved in the process of oxidation of $3 \beta$-hydroxysteroid precursors into ketosteroids. Several family members have previously been shown to be important in catalyzing an essential step in the biosynthesis of all classes of active steroid hormones [40]. The member DHRS4 was found to be highly upregulated in high androstenone boars in both Landrace and Duroc [8], and this was confirmed in an extended animal material in this study $(\mathrm{P}<0.005)$. Interestingly, the DHRS4 was very recently shown to have a role in $3 \beta$-hydroxysteroid synthesis, and DHRS4 was shown to be induced via PPAR $\alpha$ activation [41]. PPAR $\alpha$ has previously been shown to regulate various genes controlling gluconeogenesis, ketone body synthesis, heme synthesis and cholesterol metabolism [42]

Breed differences in levels of androstenone (e.g. Tajet et al. [5]), sequence variation, mRNA and protein levels have been found in several studies [43-45]. In this study we found breed differences in level of expression for the genes CYP19A2, PGRMC1 and CYP21. CYP19A2 was significantly down-regulated and PGRMC1 significantly up-regulated in high androstenone Duroc boars, while none of them were differentially expressed in Landrace. Cytochrome P450 c19 (CYP19) encodes the enzyme aromatase, which catalyses the synthesis of estrogens from androgens. Unusually high levels of estrogens are secreted from the porcine testes [46] and pig is the only mammal known to express functionally distinct isoforms of the CYP19 gene [47]. Notably, our results for the isoform CYP19A2 are not supported by previous microarray results showing up-regulation in high androstenone boars in both breeds [8]. Results in this study are based on more animals compared with the previous microarray study, and results in the current study might suggest that the significant results of differential expressions of CYP19A2 in Moe et al. [8] are false positives. Another explanation might be that other transcripts or isoforms (e.g. CYP19A1, CYP19A3) than CYP19A2 are picked up and quantified in one of the gene expression methods, although the oligo assay designed for CYP19A2 in the rcPCR experiment is made specifically to distinguish between the isoforms. The results for the PGRMC1 gene were, however, in concordance with the results reported by Moe et al. [8]. PGRMC1 is suggested to have a role in binding heme and to catalyze steroids by cytochrome $\mathrm{P} 450$ enzymes, analogous to the roles played by CYB5A (reviewed by Cahill [48]). CYP21 is a member of the cytochrome P450 superfamily enzymes, which is a key enzyme for corticosteroidogenesis [49] and suggested to have arisen evolutionary from the same gene as CYP17A1 [50]. From a physiological point of view, CYP21 leads to drastic fertility changes in human females [51]. CYP21 was significantly down regulated $(\mathrm{P}<0.02)$ in high androstenone Landrace in this study, although it is important to point out that expression levels were generally very low and the standard error high in both breeds (Tables 1 and 2). Gene expression of $C Y P 21$ in testes has previously not been studied in any species. A QTL for androstenone level of boars from a Large White/Meishan cross was detected in this region, and CYP21 was suggested as a positional candidate gene, although no polymorphisms were detected in the coding region and no association study performed [31]. An association study performed on the same populations as described in this paper detected seven SNPs within the CYP21 gene, although none of them were significantly associated with androstenone in any of the breeds [11].

The candidate genes $H S D 3 B, N C O A 4$ and SMPD1 were all chosen because they have relevant functions regarding production of androstenone. HSD3B is an enzyme catalyzing the biosynthesis of steroids in testis [52], and the enzyme has also been shown to catalyze the initial step of the hepatic metabolism of androstenone in pigs [53]. Recently, expression of the 3 $\beta$-HSD protein was shown to be repressed in liver in pigs with high androstenone, but not in testis [54]. Significantly reduced levels of mRNA expression in high androstenone Landrace and Yorkshire boars were obtained in another study [38]. In this study we were, on the other hand, not able to detect significant differences in gene expression levels of $H S D 3 B$. Furthermore, no differences in allele expression were observed, as well as none significant associations with any of the SNPs investigated (Table 4). The association results are in concordance with a recent study by Cue et al. [45], obtaining no significant associations between the $H S D 3 B$ SNPs, all located in the 5'UTR, and the androstenone level in fat from several breeds.

Nuclear receptor co-activator 4 (NCOA4; often referred to as ARA70) is identified as an androgen receptor specific co-activator [55], and is suggested to have a role in the modulation of the sex hormone specificity in humans [56]. NCOA4 was shown to be significantly up-regulated in high androstenone Duroc boars in the recent microarray study [8]. In this study, however, we were not able to confirm this result in an extended animal material, although results were close to significant $(\mathrm{P}=0.06)$. One SNP from the NCOA4 3'UTR 
region was genotyped in both populations but no significant association was observed (Table 4).

Sphingomyrlin phosphodiesterase 1 (SMPD1) is ubiquitous lysosomal hydrolase that cleaves sphingomyelin to ceramide, which again has been shown to inhibit CYP19 activity through induction of transcription factors [57]. SMPD1 was down-regulated in high androstenone Duroc animals in the microarray study [8]. This result was, however, not confirmed in the rcPCR study performed by Moe et al. [8], and not either in the current study performed on extended animal material.

Previous studies have shown that differential expression of alleles is quite common in mammals and that such variation may contribute to phenotypic variability $[12,58]$. Interestingly, $54 \%$ of tested genes were found to have preferential expression of one allele in some individuals and almost half of them showed greater than fourfold difference between the two alleles [12]. Therefore, when possible, assays were designed to allow simultaneous transcript profiling of alleles in a heterozygous individual. Five SNPs in three genes were analyzed to see whether such differentially allelic expression is present, although no significant differences were obtained (results not shown).

Summarizing this study, the genes $A K R 1 C 4, C Y B 5 A$, CYP11A1, CYP17A1, CYP19A2, CYP21, DHRS4, FTL, HSD17B4, SULT2A1, STAR and PGRMC1 were found to be differentially expressed in this study. $H S D 3 B$ was not differentially expressed in this study, contradictory to results seen in the Yorkshire breed [38]. Association between SNP and androstenone level was observed in the CYB5A gene only, suggesting cis-regulation of differential transcription. The frequency of the favorable allele is, however, very low (see Table 4), which makes it less useful for selection purposes. SNP detection needs to be performed also for the other differentially expressed genes in this study to find potentially useful markers for selection against boar taint. Previous to selection against androstenone it is, however, important also to find the relationship between the candidate SNPs and other reproduction related traits. Two of the most up regulated genes in this study, STAR and CYP17A1, have for example previously been found to be elevated in preovulatory estrogenic follicles in pigs [59]. Results in this paper suggest that several genes are important in the regulation of androstenone level in boars and warrant further evaluation of the above mentioned candidate genes, including analyses in different breeds, identification of causal mutations and possible gene interactions.

\section{Conclusion}

The gene expression of fifteen candidate genes is investigated in a large pig material of highly extreme androstenone levels. The current study contributes to new knowledge about the genes and pathways involved in regulation of androstenone in pigs, as well as contributing to important confirmation of genes previously investigated. Results highly suggest that several genes are important in the regulation of androstenone level in boars. For some of the genes the results also indicate whether there are cis- or trans regulated differences in level of transcription.

\section{Methods}

\section{Animals and Sampling}

Samples and phenotypes from 1533 Landrace and 1027 Duroc boars were included in this study, and all of them were tested in NORSVIN's (the Norwegian Pig Breeders Association) boar testing stations. The animals were reared on the standard commercial feed with an energy content of $14.9 \mathrm{MJ}$ digestible energy, $17.8 \%$ raw protein, $5.6 \%$ fiber, $6 \%$ raw fat, $6 \%$ raw ash and $1.12 \%$ lysine, without food or water restrictions. Blood samples were collected from all boars at the boar testing stations up to two weeks before slaughter. All animals were cared for according to laws and internationally recognized guidelines and regulations controlling experiments with live animals in Norway (The Animal Protection Act of December 20th, 1974, and the Animal Protection Ordinance Concerning Experiments with Animals of January 15th, 1996); according to the rules given by Norwegian Animal Research Authority.

The boars were harvested during a period of 26 months and the Landrace and Duroc boars were on average 143 and 156 days at $100 \mathrm{~kg}$ live weight, respectively. They were slaughtered 15 days later on average. Samples were taken from testicles on the slaughter line, snap frozen in liquid $\mathrm{N}_{2}$ and thereafter stored at $-80^{\circ} \mathrm{C}$. Blood samples for plasma suspension and DNA extraction were taken three days before slaughter. For androstenone measurements, samples of subcutaneous adipose tissue were collected from the neck region and stored at $-20^{\circ} \mathrm{C}$. The length of glandula bulbo urethralis was measured at the slaughter line. All boars, 2560 altogether, were included in the association study performed for the SNPs detected in 3 $\beta$-hydroxysteroid dehydrogenases (HSD3B), Cytochrome P450 subfamily XIA polypeptide 1 (CYP11A1), Cytochrome b5 (CYB5A), and nuclear receptor co-activator 4 (NCOA4), while the 192 boars with most extreme levels of androstenone were selected for gene- and allele expression studies. For gene- and allele expression 6 and 9\% of the most extreme animals in Landrace and Duroc were selected, respectively.

\section{Analyses of Androstenone}

The levels of androstenone were analyzed at the hormone laboratory at the Norwegian School of Veterinary Sciences (NVH) by a modified time-resolved fluoroimmunoassay [60], using antibody produced by Andresen 
[61]. Average androstenone levels were $1.17 \mu \mathrm{g} / \mathrm{g}(\mathrm{SD}=$ 1.10) and $3.22 \mu \mathrm{g} / \mathrm{g}(\mathrm{SD}=2.69)$ for the entire Landrace and Duroc populations, respectively.

The 192 most extreme high/low androstenone boars in both Landrace and Duroc were divided into four groups consisting of 48 individuals. The 48 high androstenone Landrace and 48 low androstenone Landrace boars had average androstenone values of $5.62 \mu \mathrm{g} / \mathrm{g}$ (SD $=1.74)$ and $0.16 \mu \mathrm{g} / \mathrm{g}(\mathrm{SD}=0.04)$, respectively. Likewise, the 48 high androstenone Duroc and 48 low androstenone Duroc boars had average androstenone values of $10.59 \mu \mathrm{g} / \mathrm{g}(\mathrm{SD}=2.47)$ and $0.39 \mu \mathrm{g} / \mathrm{g}(\mathrm{SD}=0.14)$, respectively.

\section{Nucleic acid purification and CDNA synthesis}

Total RNA was isolated from testes using the M48 (Qiagen) and treated with TURBO DNA-free ${ }^{\mathrm{TM}}$ (Ambion, Huntingdon, UK) for removal of contaminating DNA. RNA quality and concentration were determined using RNA 6000 Nano LabChip Kit on 2100 BioAnalyzer (both from Agilent Technologies, USA) and Nanodrop, ND-1000 spectrophotometer (NanoDrop Technologies, DE, USA), respectively. First strand cDNA synthesis was conducted using SuperScript ${ }^{\mathrm{m}}$-II Rnase $\mathrm{H}^{-}$Reverse Transcriptase (Invitrogen, Carlsbad, CA). $0.5 \mu \mathrm{g}$ of total RNA from each testicle sample was used as template.

DNA used for the association study was isolated from porcine leukocytes using the MagAttract DNA Blood Midi M48 protocol on the Bio-Robot M48 (Qiagen, Hilden, Germany). Concentration and quality were measured on a Nanodrop, ND-1000 spectrophotometer (NanoDrop Technologies, DE, USA) and on a 1420 Victor plate reader (Turku, Finland) using PicoGreen fluorescence (Molecular Probes, OR, USA).

\section{MassARRAY Assay Design}

The porcine gene sequences used to create a multiplexed 19-assay panel for gene- and allele-specific expression analysis via real-competitive PCR (rcPCR) and MassARRAY were annotated with respect to exon/ intron boundaries. Assays were designed such that one of the PCR primers spanned an exonic junction (to insure binding specificity to cDNA) using MassARRAY QGE Assay Design software v1.0 (SEQUENOM, San Diego, USA) for all non-polymorphic loci from each transcript. Amplicon sequences from these designs were then used as templates for a second round of assay design to create a multiplex containing the additional polymorphic loci used for allele-specific expression analysis of SNPs located in Cytochrome P450 subfamily 21 (CYP21), HSD 3B, CYB5A, and typing of CYB5A isoforms. These designs were created using the iQSNP module of the MassARRAY SNP Assay Designer software v3.0 (SEQUENOM, San Diego, USA). Primers and competitors from this design are shown in Additional files 1 and 2 .

\section{Gene expression analysis}

Real-competitive (rc) PCR gene expression analysis was used to study differential gene- and allele expression [62]. The method is based on the MassARRAY methodology, using the Quantitative Gene Expression (QGE) iPLEX system (Sequenom, San Diego, CA). The competitor, a synthetic DNA molecule matching the sequence of the targeted cDNA region at all positions except for one single base, served as an internal standard for each transcript. A 10-fold dilution of competitor was initially used over a wide range of concentrations to determine an approximate equivalence point (equal co amplification of target cDNA and competitor), followed by a 7 fold dilution of competitor from $4.04 \times 10^{-11}$ to $1.43 \times$ $10^{-19} \mathrm{M}$ (a molar concentration of $1.00 \times 10^{-18}$ is equivalent to 3 competitor molecules) to achieve more accurate measurements. The cDNA and competitor were co-amplified in the same PCR reaction with PCR conditions $95^{\circ} \mathrm{C}$ for 15 minutes, followed by 45 cycles of $95^{\circ} \mathrm{C}$ for 20 second, $56^{\circ} \mathrm{C}$ for 30 seconds and $72^{\circ} \mathrm{C}$ for 1 minute, and finally $72^{\circ} \mathrm{C}$ for 3 minutes. After a clean-up step to remove unincorporated nucleotides, the PCR products were used as templates for the primer extension reaction. The preparation of iPLEX reaction cocktail mix and PCR were performed as described in the Sequenom application guide http://www.sequenom.com/ . Parallel PCR-reactions were performed for all samples and each of the products was printed with 2 replicates on a SpectroCHIP. The primer extension reaction generates short oligonucleotides with distinct masses for competitor and cDNA-derived products, and MALDITOF mass spectrometric analysis of these DNA fragments generated signals which were quantified based on peak areas for each respective assay. To detect and confirm differentially expressed genes, hypoxanthine guanine phosphoribosyltransferase 1 (HPRT) were used as a reference transcript or 'housekeeping gene'.

\section{Allele-specific expression analysis}

Differential allele-specific expression was tested for two SNPs within the transcripts of each of the genes $C Y P 21$ and $H S D 3 B$. The CYP21 SNPs were located in exon 8 and 9 and the HSD3B SNPs were located in the 5'UTR and in exon 2 (all assays shown in Additional files 1 and 2 ). For the candidate gene CYB5A one SNP in the 5'UTR was tested for differential expression. Additionally, an assay was designed for differential transcription profiling of the CYB5A isoforms 1 and 2 .

\section{Genotyping}

SNPs were genotyped using matrix-assisted laser desorption/ionisation time-of-flight mass spectroscopy (MALDI-TOF MS) assays. Multiplex assays for use in the Sequenom MassARRAY system were designed using MassARRAY Assay Design software v3.0 (Sequenom, San Diego, USA). Primers for the genotyping are shown 
in Table 5. Genotyping was done by the IPLEX protocol using manufacturer's instructions (for complete details see iPLEX Application Note, Sequenom, San Diego). The MassARRAY Typer software was used for automated genotype calling.

\section{Statistical analysis}

\section{Gene expression}

Gene expression was quantified using the MassARRAY QGE software v3.4 (SEQUENOM, San Diego, USA) and TITAN version (1.0-13) [63] that runs in the R statistical environment. Titration of competitor concentration was used to determine the competitor concentration at which cDNA and competitor amplify equally well (EC50). The relative amounts of cDNA and competitor at each titration point were estimated by MassARRAY QGE software (Sequenom, San Diego, USA), using the mass spectra obtained. According to the Sequenom terminology the mass spectra are referred to as allele frequencies based on the calculation of the peak area ratios between extension products within each assay. The sum of all allele frequencies is equal to 1.0 for each assay [64]. For ordinary gene expression there is one frequency for the cDNA and one for the competitor. When measuring allele-specific expression, there is one cDNA frequency per allele, and one for the competitor. For the assays designed for detection of differential allele expression, the expression levels of the alleles were summed before estimation of the total gene expression level of the gene (for the assays designed for estimation of allele expression, see below). The raw data from the Genotype Analyzer Software (Sequenom) was imported into $\mathrm{R}$, where the data was preprocessed in order to remove bad data points (i.e. when no signal was detected for neither cDNA nor competitor), and the median frequency of the printing replicates were calculated. To identify differentially expressed genes, the preprocessed data were analyzed using TITAN. In TITAN the frequencies were first transformed using a log transformation $\left(y=\log _{10}(\mathrm{f} / 1-\mathrm{f})\right)$, in order to obtain a linear relationship between frequencies and the competitor concentration ( $\log 10$ scale). After that, a linear model was fitted per gene using the $\log 10$ concentration of the competitor as $\mathrm{x}$ and high/low androstenone levels as covariates. For each treatment, the model is interpolated in order to find the concentration where the amounts of
cDNA and competitor are identical. Log fold changes are calculated as the difference between high and low androstenone on the log scale. The housekeeping gene $(H P R T)$ was used for normalization. In the analysis using TITAN, default values of linear least squares polynomial regression and 4000 bootstrap replicates were used. Based on the bootstrap replicates, confidence intervals and p-values for the fold changes were calculated. The threshold for significance was set at $\mathrm{P}<0.05$. Details about the TITAN software are available from http://www.well.ox.ac.uk/ tprice/titan.

\section{Allele-specific expression}

The assays for allele-specific expression of SNPs in $C Y B 5 A$ and $H S D 3 B$ were designed to amplify transcripts of the two alleles as well as the competitor. The frequencies of the two alleles were summarized in order to get total cDNA and thus total gene expression as described above. The relative expression of allele 1 were determined as the average ratio $f_{1} /\left(f_{1}+f_{2}\right)$ across the whole titration range, where $f_{1}$ and $f_{2}$ are the frequencies of allele 1 and 2 , respectively. We used the average ratio across all titration points, since it is reasonable to assume that this ratio is constant across the titration range. In order to find whether the allele expressions were differentially expressed, the general linear model (GLM) procedure of the Statistical Analysis System (SAS) Version 9.1.3 [65] was used. Treatment (high/low androstenone) and alleles were included in the analyses as fixed effects. Results were considered to be significant at $\mathrm{P}<0.05$.

\section{Association study}

Associations between androstenone and the four candidate genes $H S D 3 B, C Y P 11 A 1, C Y B 5 A$ and $N C O A 4$ were evaluated using the GLM procedure of SAS Version 9.1 [65]. Models were fitted to identify other significant environmental and genetic effects apart from the genotypes, by elimination of non-significant effects. Levels of androstenone in fat were log-transformed to normalize the distribution of observed values. Analyses were carried out separately for the two populations using the following statistical model:

$$
\mathrm{Y}_{\mathrm{ijkl}}=\mu+\text { sire }_{\mathrm{i}}+\text { gene }_{\mathrm{j}}+\text { hys }_{\mathrm{k}}+\text { bulbo }_{\mathrm{l}}+\mathrm{e}_{\mathrm{ijkl}}
$$

where $Y_{\mathrm{ijkl}}$ is $\ln (\mathrm{ppm}$ levels of androstenone in adipose tissue) of animal $j$, offspring of sire $i$; gene ${ }_{j}$ is the fixed

Table 5 Primers used for analyzing SNP's in the candidate genes CYB5A, HSD3B, CYP11A1 and NCOA4.

\begin{tabular}{llll}
\hline SNP & SNP-Localization & Forward primer & Reverse primer \\
\hline CYB5A_-8(5'UTR) & $-8,5^{\prime}$ UTR & CTCTGTTCCGCTCATCTCTG & ATACTTCACGGCTTGTCGG \\
HSD3B_-15(5'UTR) & $-15,5^{\prime}$ UTR & TCCCCAGTGTTTCTGGTTC & CCATCCAGCCATTGCTAAAC \\
HSD3B_271-exon2 & 271, exon2 & TCATCCACACTGCCTCTATC & TTGACCTTCATGACGGTCTC \\
CYP11A1_150-exon1 & 150, exon1 & TGCATCTCCACTAAAACCCC & ACGGTACAGGTTAATCCAGC \\
NCOA4_3'UTR & $3^{\prime}$ UTR & TGCAGTCCCAGTGTCATTAC & GTTCTAAATGGTATCTGGGG \\
\hline
\end{tabular}


effect of the candidate gene genotype; hys $\mathrm{k}_{\mathrm{k}}$ is the fixed effect of herd/year/season, and bulbo is the random effect of glandula bulbo urethralis. Sire was included as fixed effect in the model to ensure that the genotype effects were not confounded with selection in the sires. The length of glandula bulbo urethralis is taken into account because it is highly correlated with the level of sexual maturation in boars [66]. Least squares means were estimated for each genotype and overall $\mathrm{F}$ tests were used to determine level of significance. Back-transformed leastsquares mean without further corrections are presented in Table 4, thus giving the medians in the original skewed distributions. Results were considered to be significant at $\mathrm{P}<0.05$. Standard errors are supplied in the Table 4 . Furthermore, a chi-square test was conducted to test whether any of the SNPs were diverging from HardyWeinberg equilibrium.

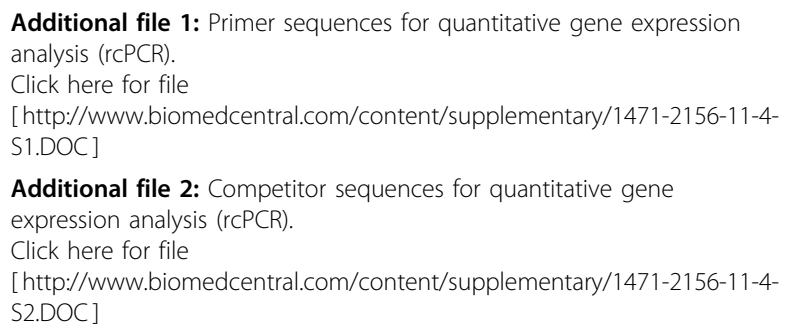

Additional file 2: Competitor sequences for quantitative gene expression analysis (rCPCR).

Click here for file

[http://www.biomedcentral.com/content/supplementary/1471-2156-11-4S2.DOC ]

\begin{abstract}
Acknowledgements
This work was financed by NORSVIN (the Norwegian pig breeders association) and the Research Council of Norway. The authors gratefully acknowledge Elin Bergseth (NORSVIN/BIOBANK AS) for collecting and handling the samples, Marianne Hansen (NORSVIN) for technical assistance in the lab, and Ellen Dahl and Øystein Andresen for being in charge of analyses at the hormone laboratory at the Norwegian School of Veterinary Science (NVH)

\section{Author details}

${ }^{1}$ NORSVIN (The Norwegian Pig Breeders Association), Hamar, Norway. ${ }^{2}$ Centre for Integrative Genetics (CIGENE), Norwegian University of Life Sciences, Ås, Norway. ${ }^{3}$ Research and Development, Sequenom, Inc., San Diego, CA. 92121, USA. ${ }^{4}$ Department of Animal and Aquacultural Sciences, Norwegian University of Life Sciences, Ås, Norway.
\end{abstract}

\section{Authors' contributions}

EG conducted the molecular work, performed statistical analyses and drafted the manuscript. IB did statistical supervision and carried out the programming involved. MM was involved in the molecular work. PO carried out the assay design for gene- and allele expression analyses. SL was involved in planning the project, provided laboratory facilities and took part in writing the paper. All authors read and approved the final manuscript.

Received: 17 September 2009

Accepted: 25 January 2010 Published: 25 January 2010

\section{References}

1. Claus R, Weiler U, Herzog A: Physiological aspects of androstenone and skatole formation in the boar-A review with experimental data. Meat Science 1994, 38(2):289-305
2. Gower DB: 16-Unsaturated C 19 steroids. A review of their chemistry, biochemistry and possible physiological role. Journal of Steroid Biochemistry 1972, 3:45-103.

3. Brooks Rl, Pearson AM: Steroid hormone pathways in the pig, with special emphasis on boar odor: a review. J Anim Sci 1986, 62(3):632-645

4. Willeke $\mathrm{H}$ : Possibilities of breeding for low $5 \alpha$-androstenone content in pigs. Pigs news and information 1993, 14:31-33.

5. Tajet $H$, Andresen $\varnothing$, Meuwissen T: Prevention of boar taint in pig production: the 19th symposium of the nordic committee for veterinary scientific cooperation Gardermoen, Norway. Acta Veterinaria Scandinavica Supplement 2005, 48(Suppl 1):P1-6, S1-16.

6. Robic A, Larzul C, Bonneau M: Genetic and metabolic aspects of androstenone and skatole deposition in pig adipose tissue: a review. Genet Sel Evol 2008, 40(1):129-143.

7. Zamaratskaia G, Squires J: Biochemical, nutritional and genetic effects on boar taint in entire male pigs. Animal 2009, 3(11):1508-1521.

8. Moe M, Meuwissen T, Lien S, Bendixen C, Wang X, Conley LN, Berget I, Tajet $H$, Grindflek E: Gene expression profiles in testis of pigs with extreme high and low levels of androstenone. BMC Genomics 2007, 8:405.

9. Morley M, Molony CM, Weber TM, Devlin JL, Ewens KG, Spielman RS, Cheung VG: Genetic analysis of genome-wide variation in human gene expression. Nature 2004, 430(7001):743-747.

10. Stranger BE, Forrest MS, Clark AG, Minichiello MJ, Deutsch S, Lyle R, Hunt S, Kahl B, Antonarakis SE, Tavare S, et al: Genome-wide associations of gene expression variation in humans. PLoS Genet 2005, 1(6):e78.

11. Moe M, Lien S, Aasmundstad T, Meuwissen THE, Hansen MHS, Bendixen C, Grindflek E: Association between SNPs within candidate genes and compounds related to boar taint and reproduction. BMC Genetics 2009, 10(32).

12. Lo HS, Wang Z, Hu Y, Yang HH, Gere S, Buetow KH, Lee MP: Allelic variation in gene expression is common in the human genome. Genome Res 2003, 13(8):1855-1862.

13. Katkov T, Gower DB: The biosynthesis of androst-16-enes in boar testis tissue. Biochem J 1970, 117(3):533-538.

14. Meadus W, Mason J, Squires E: Cytochrome P450c17 from porcine and bovine adrenal catalyses the formation of 5,16-androstadien-3 beta-ol from pregnenolone in the presence of cytochrome b5. J Steroid Biochem Mol Biol 1993, 46(5):565-572.

15. Lin Z, Lou Y, Peacock J, Squires EJ: A novel polymorphism in the $5^{\prime}$ untranslated region of the porcine cytochrome b5 (CYB5) gene is associated with decreased fat androstenone level. Mamm Genome 2005, 16(5):367-373.

16. Davis S, Squires E: Association of cytochrome b5 with 16-androstene steroid synthesis in the testis and accumulation in the fat of male pigs. $J$ Anim Sci 1999, 77(5).

17. Zamaratskaia G, Lou Y, Peacock J, Rydhmer L, Andersson HK, Juneja RK, Chen G, Lundstrom K, Squires EJ: Effect of polymorphism in the porcine cytochrome b5 (CYB5A) gene on androstenone and skatole concentrations and sexual development in Swedish pig populations. Animal 2008, 2(2):190-196.

18. VanDerMark PK, Steggles AW: The isolation and characterization of the soluble and membrane-bound porcine cytochrome b5 cDNAs. Biochem Biophys Res Commun 1997, 240(1):80-83.

19. Giordano SJ, Steggles AW: Differential expression of the mRNAs for the soluble and membrane-bound forms of rabbit cytochrome b5. Biochim Biophys Acta 1993, 1172(1-2):95-100.

20. Peacock J, Lou Y, Lundstrom K, Squires EJ: The effect of a c.-8G>T polymorphism on the expression of cytochrome b5A and boar taint in pigs. Anim Genet 2008, 39(1):15-21.

21. Schenkman JB, Jansson I: The many roles of cytochrome b5. Pharmacol Ther 2003, 97(2):139-152.

22. Bonfils C, Balny C, Maurel P: Direct evidence for electron transfer from ferrous cytochrome b5 to the oxyferrous intermediate of liver microsomal cytochrome P-450 LM2. J Biol Chem 1981, 256(18):9457-9465.

23. Hentze MW, Kuhn LC: Molecular control of vertebrate iron metabolism: mRNA-based regulatory circuits operated by iron, nitric oxide, and oxidative stress. Proc Natl Acad Sci USA 1996, 93(16):8175-8182.

24. Lin Z, Lou $Y$, Squires EJ: Identification of a single nucleotide polymorphism in porcine testis cytochrome P450-c17 (CYP17) and its effect on steroidogenesis. Biochem Genet 2005, 43(9-10):531-542. 
25. Christenson LK, Strauss JF: Steroidogenic acute regulatory protein (StAR) and the intramitochondrial translocation of cholesterol. Biochim Biophys Acta 2000, 1529(1-3):175-187.

26. Miller WL: Mitochondrial specificity of the early steps in steroidogenesis J Steroid Biochem Mol Biol 1995, 55(5-6):607-616.

27. Pilon N, Daneau I, Brisson C, Ethier JF, Lussier JG, Silversides DW: Porcine and bovine steroidogenic acute regulatory protein (StAR) gene expression during gestation. Endocrinology 1997, 138(3):1085-1091.

28. Blomberg LA, Zuelke KA: Expression analysis of the steroidogenic acute regulatory protein (STAR) gene in developing porcine conceptuses. Mol Reprod Dev 2005, 72(4):419-429.

29. Irusta G, Parborell F, Peluffo M, Manna PR, Gonzalez-Calvar SI, Calandra R, Stocco DM, Tesone M: Steroidogenic acute regulatory protein in ovarian follicles of gonadotropin-stimulated rats is regulated by a gonadotropinreleasing hormone agonist. Biol Reprod 2003, 68(5):1577-1583.

30. Greger D, Antle S, Plath-Gabler A, Gutshall K, Mills E, Hammerstedt R, Hagen D, Baumrucker C: Identification of a porcine CYP11A1 polymorphism and associations with steroid concentrations and reproductive traits in pigs. Plant \& Animal Genome IX Conference, San Diego, CA 2001.

31. Quintanilla R, Demeure O, Bidanel JP, Milan D, lannuccelli N, Amigues $Y$, Gruand J, Renard C, Chevalet C, Bonneau M: Detection of quantitative trait loci for fat androstenone levels in pigs. J Anim Sci 2003, 81(2):385-394.

32. Sinclair PA, Squires EJ: Testicular sulfoconjugation of the 16-androstene steroids by hydroxysteroid sulfotransferase: its effect on the concentrations of 5alpha-androstenone in plasma and fat of the mature domestic boar. J Anim Sci 2005, 83(2):358-365.

33. Sinclair P, Gilmore W, Lin Z, Lou Y, Squires E: Molecular cloning and regulation of porcine SULT2A1: relationship between SULT2A1 expression and sulfoconjugation of androstenone. J Mol Endocrinol 2006, 36(2):301-311.

34. Payne $\mathrm{AH}$, Hales DB: Overview of steroidogenic enzymes in the pathway from cholesterol to active steroid hormones. Endocr Rev 2004, 25(6):947-970

35. Carstensen JF, Tesdorpf JG, Kaufmann M, Markus MM, Husen B, Leenders F, Jakob F, de Launoit Y, Adamski J: Characterization of 17 betahydroxysteroid dehydrogenase IV. J Endocrinol 1996, 150(Suppl):S3-12.

36. Kaufmann M, Carstensen J, Husen B, Adamski J: The tissue distribution of porcine 17 beta-estradiol dehydrogenase and its induction by progesterone. J Steroid Biochem Mol Biol 1995, 55(5-6):535-539.

37. Adamski J, Normand T, Leenders F, Monte D, Begue A, Stehelin D, Jungblut PW, de Launoit Y: Molecular cloning of a novel widely expressed human $80 \mathrm{kDa} 17$ beta-hydroxysteroid dehydrogenase IV. Biochem J 1995, 311(Pt 2):437-443.

38. Chen G, Bourneuf E, Marklund S, Zamaratskaia G, Madej A, Lundstrom K: Gene expression of 3\{beta\}-hydroxysteroid dehydrogenase and 17\{beta\}hydroxysteroid dehydrogenase in relation to androstenone, testosterone, and estrone sulphate in gonadally-intact male and castrated pigs. J Anim Sci 2007, 85(10):2457-2463.

39. Penning TM, Burczynski ME, Jez JM, Hung CF, Lin HK, Ma H, Moore M, Palackal N, Ratnam K: Human 3alpha-hydroxysteroid dehydrogenase isoforms (AKR1C1-AKR1C4) of the aldo-keto reductase superfamily: functional plasticity and tissue distribution reveals roles in the inactivation and formation of male and female sex hormones. Biochem J 2000, 351(Pt 1):67-77.

40. Penning TM: Molecular endocrinology of hydroxysteroid dehydrogenases. Endocr Rev 1997, 18(3):281-305.

41. Matsunaga T, Endo S, Maeda S, Ishikura S, Tajima K, Tanaka N, Nakamura KT, Imamura Y, Hara A: Characterization of human DHRS4: an inducible short-chain dehydrogenase/reductase enzyme with 3betahydroxysteroid dehydrogenase activity. Arch Biochem Biophys 2008, 477(2):339-347.

42. Michalik L, Auwerx J, Berger JP, Chatterjee VK, Glass CK, Gonzalez FJ, Grimaldi PA, Kadowaki T, Lazar MA, O'Rahilly S, et al: International Union of Pharmacology. LXI. Peroxisome proliferator-activated receptors. Pharmacol Rev 2006, 58(4):726-741.

43. Moe M, Grindflek E, Doran O: Expression of 3 \{beta\}-hydroxysteroid dehydrogenase, cytochrome $\mathrm{P} 450 \mathrm{c} 17$ and sulfotransferase $2 \mathrm{~B} 1$ proteins in liver and testis of pigs of two breeds: relationship with adipose tissue androstenone concentration. J Anim Sci 2007, 85(11):2924-2931.
44. Xue J, Dial G, Holton E, Vickers Z, Squires E, Lou Y, Godbout D, Morel N: Breed differences in boar taint: relationship between tissue levels boar taint compounds and sensory analysis of taint. Journal of Anim Science 1996, 74(9):2170-2177.

45. Cue R, Nicolau-Solano S, McGivan J, Wood J, Doran O: Breed-associated variations in the sequence of the pig 3beta-hydroxysteroid dehydrogenase gene. Journal of Animal Science 2007, 85(3):571-576.

46. Claus R, Hoffman B: Oestrogens, compared to other steroids of testicular origin, in bloodplasma of boars. Acta Endocrinologica 1980, 94:404-411.

47. Corbin CJ, Khalil MW, Conley AJ: Functional ovarian and placental isoforms of porcine aromatase. Mol Cell Endocrinol 1995, 113(1):29-37.

48. Cahill MA: Progesterone receptor membrane component 1: An integrative review. J Steroid Biochem Mol Biol 2007, 105(1-5):16-36.

49. Crawford RJ, Hammond VE, Connell JM, Coghlan JP: The structure and activity of two cytochrome $\mathrm{P} 450 \mathrm{C} 21$ proteins encoded in the ovine adrenal cortex. J Biol Chem 1992, 267(23):16212-16218.

50. Picado-Leonard J, Miller WL: Cloning and sequence of the human gene for P450c17 (steroid 17 alpha-hydroxylase/17,20 lyase): similarity with the gene for P450c21. DNA 1987, 6(5):439-448.

51. New Ml: Steroid 21-hydroxylase deficiency (congenital adrenal hyperplasia). Am J Med 1995, 98(1A):2S-8S.

52. Payne $A H$, Youngblood $G L$ : Regulation of expression of steroidogenic enzymes in Leydig cells. Biol Reprod 1995, 52(2):217-225.

53. Doran E, Whittington FM, Wood JD, McGivan JD: Characterisation of androstenone metabolism in pig liver microsomes. Chem Biol Interact 2004, 147(2):141-149.

54. Nicolau-Solano S, McGivan J, Whittington F, Nieuwhof G, Wood J, Doran O: Relationship between the expression of hepatic but not testicular 3betahydroxysteroid dehydrogenase with androstenone deposition in pig adipose tissue. J Anim Sci 2006, 84(10):2809-2817.

55. Yeh $S$, Chang C: Cloning and characterization of a specific coactivator, ARA70, for the androgen receptor in human prostate cells. Proc Natl Acad Sci USA 1996, 93(11):5517-5521.

56. Yeh $\mathrm{S}$, Miyamoto $\mathrm{H}$, Shima $\mathrm{H}$, Chang $\mathrm{C}$ : From estrogen to androgen receptor: a new pathway for sex hormones in prostate. Proc Natl Acad Sci USA 1998, 95(10):5527-5532.

57. Santana P, Llanes L, Hernandez I, Gallardo G, Quintana J, Gonzalez J, Estevez F, Ruiz de Galarreta C, Fanjul LF: Ceramide mediates tumor necrosis factor effects on P450-aromatase activity in cultured granulosa cells. Endocrinology 1995, 136(5):2345-2348.

58. Yan H, Yuan W, Velculescu VE, Vogelstein B, Kinzler KW: Allelic variation in human gene expression. Science 2002, 297(5584):1143.

59. Agca C, Ries JE, Kolath SJ, Kim JH, Forrester LJ, Antoniou E, Whitworth KM, Mathialagan N, Springer GK, Prather RS, et al: Luteinization of porcine preovulatory follicles leads to systematic changes in follicular gene expression. Reproduction 2006, 132(1):133-145.

60. Tuomola M, Harpio R, Knuuttila P, Mikola H, Løvgren T: Time-resolved fluoroimmunoassay for the measurement of androstenone in porcine serum and fat samples. Journal of agricultural food chemistry 1997, 45:3529-3534

61. Andresen $\varnothing$ : Development of radioimunoassay for 5alpha-adrost-16-en-3one in pig peripheral plasma. Acta endochrinologia 1974, 76:377-387.

62. Ding C, Cantor CR: A high-throughput gene expression analysis technique using competitive PCR and matrix-assisted laser desorption ionization time-of-flight MS. Proc Natl Acad Sci USA 2003, 100(6):3059-3064.

63. Elvidge G, Price T, Glenny L, Ragoussis J: Development and evaluation of real competitive PCR for high-throughput quantitative applications. Anal Biochem 2005, 339(2):231-241.

64. Jurinke $C$, Oeth $P$, Boom van den D: MALDI-TOF mass spectrometry: a versatile tool for high-performance DNA analysis. Molecular Biotechnology 2004, 26:147-164.

65. SAS: SAS 9.1.3. Help and Documentation. Cary, NC: SAS Institute Inc 2007.

66. Sellier P, Le Roy P, Fouilloux MN, Gruand J, Bonneau M: Responses to restricted index selection and genetic parameters for fat androstenone level and sexual maturity status of young boars. Livstestock Production Science 2000, 63:265-274.

doi:10.1186/1471-2156-11-4

Cite this article as: Grindflek et al:: Transcript profiling of candidate genes in testis of pigs exhibiting large differences in androstenone levels. BMC Genetics 2010 11:4. 